\title{
Chapter 6 \\ Innovating at Marketing and Distributing \\ Nutritious Foods at the Base \\ of the Pyramid (BoP): Insights \\ from 2SCALE, the Largest Incubator \\ for Inclusive Agribusiness in Africa
}

\author{
Niek van Dijk, Nick van der Velde, Janet Macharia, Kwame Ntim Pipim, \\ and Hiwot Shimeles
}

\subsection{A Brief Description of 2SCALE}

The Netherlands-funded "Toward Sustainable Clusters in Agribusiness through Learning in Entrepreneurship" (2SCALE) is an incubator program that manages a portfolio of public-private partnerships (PPPs) for inclusive business in agri-food sectors and industries and ultimately to improve rural livelihoods and food and nutrition security. 2SCALE offers a range of support services to its business champions (small to medium enterprises [SMEs] and farmer groups) and partners in eight countries across sub-Saharan Africa, enabling them to produce, transform, and supply quality food products. These products go to local and regional markets, including to base of the pyramid (BoP) consumers.

Project support includes technology transfer, capacity strengthening, and market linkages, as well as other key elements such as improving access to finance - vital but often sorely lacking in the smallholder sector.

Its implementing partners are (1) BoP Innovation Center (BoPInc) which supports companies and entrepreneurs to develop relevant products and services for and with the base of the pyramid (BoP). Its mission is to develop commercially and socially viable business models and activities which include the people in the BoP as consumers, producers, and entrepreneurs. (2) The Inclusive Green Growth Department (IGG) from the Ministry of Foreign Affairs of the Netherlands, which aims to ensure universal access to and wise use of natural resources. IGG is responsible for the Dutch foreign policy on the following themes: climate, water, food We would like to sincerely thank Mahamane Toure and Maryse Ago da Silva who, along with
authors, generously provided pictures to this chapter.

N. van Dijk $\cdot$ N. van der Velde $(\bowtie) \cdot$ J. Macharia $\cdot$ K. N. Pipim $\cdot$ H. Shimeles

BoP, Inc., Utrecht, The Netherlands

e-mail: vandervelde@ bopinc.org 
security, energy, raw materials, and the polar regions. (3) The International Fertilizer Development Center (IFDC), a public international organization addressing critical issues such as food security, the alleviation of global hunger and poverty, environmental protection, and the promotion of economic development and self-sufficiency. (4) SNV (Netherlands Development Organisation) is dedicated to a society in which all people, regardless of race, class, or gender, enjoy the freedom to pursue their own sustainable development. We focus on increasing people's incomes and employment opportunities in productive sectors like agriculture as well as on improving access to basic services such as energy, water, sanitation, and hygiene.

\subsection{BoP Marketing and Distribution in 2SCALE}

In this section, we introduce the concept of base of the pyramid (BoP) and explain why, from both a developmental perspective and a business perspective, it makes sense to do business with and for BoP consumers. In ensuing sections, we explain why 2SCALE focuses on marketing and distribution to the BoP, how pilots are shaped within the program to introduce this way of working to business champions, and, in turn, how we continuously learn from testing this particular approach.

\subsubsection{The BoP as a Developmental Challenge and Business Opportunity}

The term "base of the pyramid," or "bottom of the pyramid," was first coined by CK Prahalad in his groundbreaking publication entitled The Fortune at the Bottom of the Pyramid: Eradicating Poverty Through Profits (Prahalad 2009). At that time, much was unknown about this market segment, but the interest generated by Prahalad's book ensured that during the years thereafter, the BoP became a topic of interest for many researchers and later for companies and nongovernmental organizations (NGOs).

One of the main reasons the book gained so much attention was that it was the first time a rationale had been built on why the BoP market was important. From a business perspective, it was interesting to gain a deeper understanding of the global economy's lowest income segment - a segment of around 4 billion consumers who live on less than US $\$ 1,500$ per year.

One of the key findings of the book was that if and when companies and other stakeholders want to engage with the BoP, it requires a completely different approach in comparison to other market segments; even more so, it would "require radical innovations in technology and business models."

\footnotetext{
${ }^{1}$ https://www.strategy-business.com/article/11518?gko=9a4ba
} 
To grasp a sense of how substantial the BoP market is from a financial perspective and to better understand the breakdown of market potential per sector, the International Finance Corporation (IFC) and World Resources Institute (WRI) shared the results of a key study on the BoP in 2007. The study revealed that the total consumer market size of the BoP, which remained largely untapped by companies at the moment, was valued at a staggering $\$ 5$ trillion. The study placed the total value of the BoP market for food products in sub-Saharan Africa at \$215 billion. This constitutes a huge new market potential for food-producing companies and farmer organizations targeting the African market.

At the same time, most BoP consumers are a part of the same group as the 821 million people who are undernourished globally. ${ }^{2}$ Therefore, targeting lowincome food consumers makes sense not only from a business perspective but also from a developmental perspective. Undernourishment should not be tackled purely by developmental interventions, such as food aid, but by using market-driven approaches that build upon viewing this vast group of 821 million as BoP consumers. These consumers, as Prahalad stated, are the "aspiring poor" - a group of consumers with very little to spend but highly aspirational in their purchasing decisions, making them also highly critical consumers.

\subsubsection{Marketing Toward the BoP}

As we described above, the BoP is quite a different consumer segment compared to others and therefore requires a different approach - a different type of marketing. Typically, in marketing, the 4Ps (product, price, place, promotion) approach is used. Instead, at 2SCALE we use the 4As (acceptability, affordability, awareness, availability) to cater to the different challenges and opportunities companies face in marketing their products to the BoP. The 4As approach also provides a better base for analyzing the unique challenges that BoP consumers themselves face when, for instance, making purchasing decisions. Altogether, the 4As approach provides an opportunity for a more in-depth and consumer-centric analysis of what it means to market products with and for the BoP. To have a successful marketing approach for the BoP, all four dimensions must be taken into consideration:

- Acceptability: Ensuring that the product is accepted by the end consumer. It requires an in-depth understanding of the consumer's needs, dominant behaviors, and customs.

- Affordability: Offering products at a price point that meets the purchasing power of the BoP. Interestingly, it has been proven that consumers at the BoP are willing to pay a slightly higher price for nutritious foods, if they understand the products' benefits. $^{3}$

\footnotetext{
${ }^{2} 2018$ FAO The State of Food Security and Nutrition in the World: http://www.fao.org/state-offood-security-nutrition/en

${ }^{3}$ Hystra: http://hystra.com/marketing-nutrition, pages 17 and following.
} 
- Awareness: Making sure consumers know about the product and its benefits. In the process of creating awareness, it is key to identify any trusted channels.

- Availability: Making the product available to the BoP by building specific distribution channels, often requiring an innovative approach to reach remote and more informally organized BoP markets.

The 4As are better suited for the position in which BoP consumers find themselves. Oftentimes they are located in areas farther from typical markets or commercial centers than other market segments. Therefore, availability is important. As the BoP is also less connected to "mainstream" media than other consumer segments, companies need to take extra steps to promote their products to BoP consumers. In addition, BoP consumers have relatively lower purchasing power, so affordability is even more important to them than to other consumer segments.

In relative terms, food represents for BoP consumers a much larger share of their expenditure compared to other consumer segments - i.e., in Nigeria BoP households spend over $70 \%$ of their disposable income on food and beverages. ${ }^{4}$ Lastly, companies will need to ensure that their products and services fit with the perceptions, traditions, and aspirations of BoP consumers, and these can often be quite different from other consumer segments. Business champions will have to make a greater effort, or take a different approach, in their marketing and communication to ensure that BoP consumers also accept the product.

Even though the BoP market might be more difficult to reach and requires dedicated effort, it also holds great potential. BoP marketing and distribution strategies provide business opportunities to companies as well as an opportunity to improve the food and nutrition security of an important population segment. BoP consumers are usually not perceived or targeted as potential consumers. Companies often do not perceive this market segment as an opportunity for generating profit due to their relatively low purchasing power. On top of the huge untapped economic potential, there is also a major development opportunity in providing nutritious food products to BoP consumers.

\subsubsection{BoP Marketing and Distribution Within the Context of 2SCALE}

A common driver across all 2SCALE activities is the market, providing either supply chains with thousands of smallholder farmers as end buyers or food product value chains targeting rural and urban food consumers. Value chain development with specific attention to BoP consumers also must be market driven to be successful. An important distinction is that the market opportunity offered by the BoP is not always (fully) recognized by value chain actors. Many of 2SCALE's partners have

\footnotetext{
${ }^{4}$ https://blog.euromonitor.com/2017/03/top-5-bottom-pyramid-markets-diverse-spending-patterns-future-potential.html
} 
been serving high-end markets or business-to-business (B2B) markets in their countries or regions and therefore do not necessarily know how to reach BoP consumers. In addition, the business case can be quite different, requiring the development of specific or new product propositions for BoP consumers. While individual BoP consumers may have little purchasing power and therefore be more inclined to buy small quantities of product (sometimes referred to as "Kadogo Economy"), ${ }^{5}$ the number of consumers and their market share are what drive economies of scale and profits for value chain actors (Boxes 6.1 and 6.2).

\section{Box 6.1 BoP Marketing and Distribution - Theme: Women's Empowerment}

The empowerment of women within agribusiness value chains is one of the main goals of 2SCALE. As discussed throughout this paper, developing BoP marketing and distribution activities can create both entrepreneurship as well as employment opportunities for women, beyond more "conventional" opportunities in agricultural value chains, such as factory workers and casual laborers. Good examples of this are the Likie Ladies, micro-entrepreneurs who have formed a network of last-mile distributors for business champion GUTS Agro in Ethiopia, and the Danaya women's processor cooperative, which built a strengthened business network out of the BoP marketing activities in Mali. In the future, 2SCALE plans to develop more activities that also empower female BoP consumers, primarily the female heads of households, through behavioral change campaigns and other activities.

\section{Box 6.2 BoP Marketing and Distribution - Theme: Access to Finance}

One of the challenging dynamics in BoP marketing pilots is access to finance or, more specifically, access to working capital. For instance, the microentrepreneurs who are involved in the sale and distribution of BoP food products often have limited access to working capital, making it difficult for them to buy stock. This can limit the demand for food products from business champions. Also, BoP consumers do not always have a steady income, sometimes limiting their ability to buy food, and micro-entrepreneurs often are not willing to sell food products on credit.

(continued) ${ }^{5}$ http://corporatewatch.co.ke/wrigley-launches-smaller-sized-skittles-kadogo-economy/ provides
a Kenyan example. 
(continued)

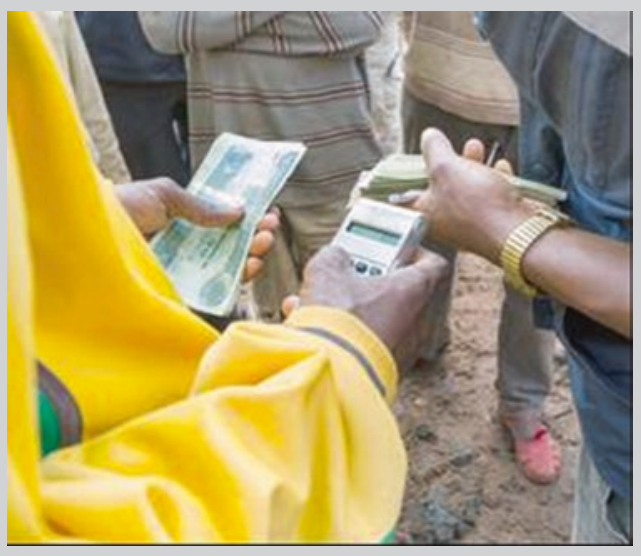

In the near future, 2SCALE will look into opportunities related to working capital needs of micro-retailers to keep stock and consumer finance opportunities, among others, by learning from interesting initiatives in the same field, such as the collaboration between Twiga Foods and IBM in Kenya.

Photo credit: USAID Ethiopia, Creative Commons AttributionNonCommercial 2.0 Generic - creativecommons.org/licenses/by-nc/2.0/ Image cropped and brightened.

In 2SCALE in general, we work together with business champions to realize their inclusive business ideas by setting up partnerships that involve different actors across the broader value chain. Such a business champion is either a small to medium enterprise (SME) or a farmer organization. Their business ideas can focus on involving more smallholder farmers, doing more business with microentrepreneurs, reaching more BoP consumers, or any other ways to make their operations and their broader value chain more inclusive. By developing a partnership that involves a broader range of actors (including financial institutions, input providers, and others), systemic change can be realized. ${ }^{6}$

Because the concept of BoP markets and the opportunities they hold are still relatively new for most 2SCALE business champions, the BoP consumer segment is always introduced in a pilot setting, within the broader context of a 2SCALE partnership. In this way, the business champion can be introduced to the potential of this market segment and experiment with approaches on how to reach the BoP. In this they are supported by 2SCALE to lower the risks that come with developing new products or marketing approaches to reach a new consumer segment.

\footnotetext{
${ }^{6} \mathrm{https}: / /$ www.2scale.org/upload/7479bf_2SCALE_paper1.pdf
} 


\subsubsection{What Have We Achieved So Far}

In the early stages of 2SCALE, the focus was mostly on developing and implementing a market research methodology to gain market information and insights on BoP food markets (focusing on specific crops) in different 2SCALE countries. Though this research was quite detailed, it did not necessarily lead to direct, actionable insights for 2SCALE business champions. The approach was therefore changed, leading to a more action-oriented approach that eventually led to the implementation of 24 different BoP marketing and distribution pilots. These pilots were quite diverse in nature, ranging from small pilots with small-scale groups in groundnut processing to large pilots with established SMEs in packaged processed food products. In total, through different pilot activities (from market promotions to new product development), 2SCALE delivered the following results:

- Thirty-seven new product propositions for the BoP were introduced by 24 different business champions.

- In total, over a million of these new products were sold, often within a short pilot time span, substantially increasing the turnover of the business champions.

- Close to 250,000 BoP consumers were reached through different market activations and communication campaigns.

- Business champions directly created over 200 new jobs through BoP marketing and distribution activities (i.e., as sales agents, micro-distributors, and marketers).

\subsection{How BoP Marketing Activities Are Developed Within 2SCALE}

Thus far, BoP marketing activities have been implemented in 2SCALE in the form of pilots. The process of designing and implementing a BoP marketing pilot always takes place within the broader context of a 2SCALE partnership. For most 2SCALE partnerships, a general notion of the relevance of BoP markets is included when the partnership idea is developed and designed, and later it is described in more detail in the partnership description.

Subsequently, when the partnership agreement is signed and the partnership is ready for implementation, activities to implement the partnership are identified and developed into an annual action plan. It is in this process of action plan development that the BoP marketing activities also take shape in more detail.

The development of these BoP marketing activities, within the broader context of partnership agreements and action plan development, roughly follows five steps (Fig. 6.1) which are implemented together with the business champion. Even though every BoP marketing pilot is different because of differences in markets, geography, business partners, etc., the process of building a BoP marketing pilot follows a common path. 


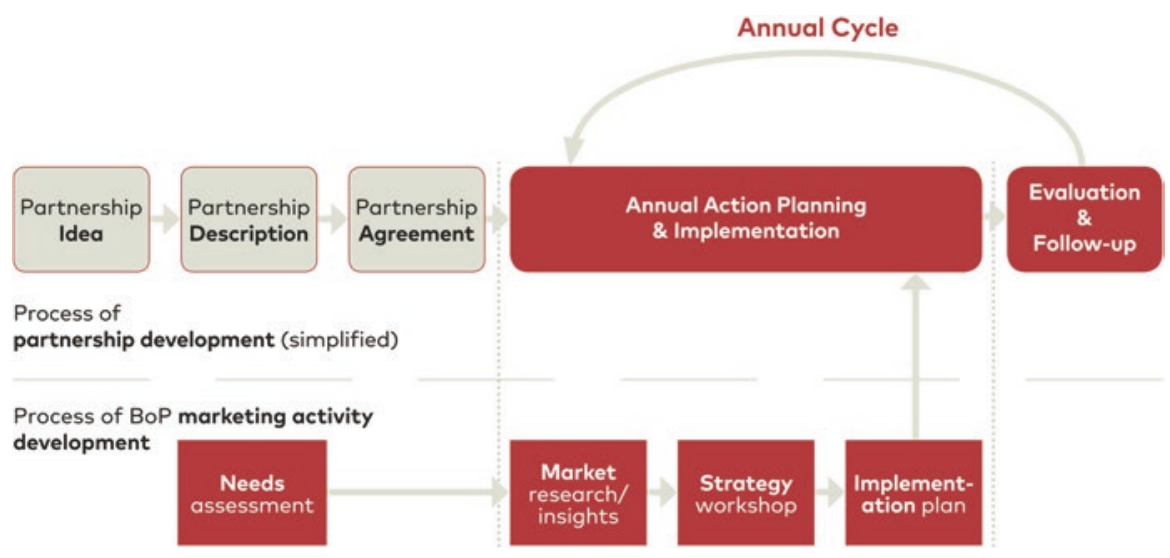

Fig. 6.1 Five-step process of designing and implementing a BoP marketing pilot

\subsubsection{Conducting Needs Assessments}

The first step in the process is to deeply engage with the business champion to get a joint and detailed understanding of his or her business and vision for targeting BoP consumers with nutritious food products. For the business champion to get a realistic understanding of what a BoP marketing pilot could look like in the context of 2SCALE, several cases of previous 2SCALE pilots are shared and described throughout this chapter. These practical examples often resonate well with the champion, since they include tangible learnings and also demonstrate the "business" results of targeting the BoP.

Another important part of the assessment is visiting the business champion's premises to gain insight about the current conditions under which the business champion is manufacturing products. There is not a formal assessment methodology that is used. Instead, specific attention is paid to the features that are relevant to designing the BoP marketing pilot. These features mainly relate to the champion's capacity in sourcing, production, marketing, distribution, and finance. For instance, it makes a large difference if an operational processing and packing facility already is in place. When such facilities are lacking, the 2SCALE teams know the implications in terms of required activities, timelines, and finance.

\subsubsection{Market Research and Insight Gathering}

The second step is to conduct market research and collect insights into consumer behavior in the particular market (and on the particular food product) that the business champion is active in. ${ }^{7}$ These insights can also help provide an understanding

\footnotetext{
${ }^{7} \mathrm{http} / / /$ www.bopinc.org/sites/www.bopinc.org/files/updates/bop_insights_publication.pdf, for an account of the importance of gathering consumer insights.
} 
of how a food product can improve the nutritional status of the targeted consumers, for instance, by making critical nutrients available or by making certain nutritional food products more affordable. ${ }^{8}$ In addition, it is important that the market research and insights not become too generic and can provide actionable insights for the business champion to design the BoP marketing pilot. For example, one could question whether a small dairy cooperative that wants to develop affordable yoghurt requires extensive data on the national dairy market. Instead, the cooperative might be better off with a detailed understanding of the competitive yoghurt market in their specific location.

Overall, there are three important areas that are covered during this phase. First, there must be a general understanding of the market and the broader business environment. This should not be too generic but rather limited in its scope. Second, the competitive landscape will need to be understood in detail (e.g., which other companies provide similar products, what are their characteristics and pricing). Lastly, it is essential to have a detailed understanding of consumer characteristics, consumption, and purchasing behavior.

The goal of 2SCALE is to make the research phase as actionable as possible. Therefore, research is done in close collaboration with the business champion. The results of this phase are also actively discussed during the strategy workshop (see below), for instance, by purchasing and bringing along any competitive products to the workshop. The research and insights phase helps champions develop their BoP marketing strategy and design activities.

\subsubsection{Strategy Workshop}

After the research is finalized, all insights are brought together in a strategy workshop in which the key members of the business champion's management team are present. The most important aspect of this workshop is that it is co-creative, meaning that all content is being developed by the business champion's team together with 2SCALE.

The general approach of the workshop is to start mapping out the business champion's organization. To do so, 2SCALE uses the Business Model Canvas (BMC). This is a convenient model that has proven to be well understood by various business champions and provides actionable building blocks for a strategy. The most important building blocks of the $\mathrm{BMC}$ are the customer persona, value proposition, and marketing and distribution. For more information on these key components, please refer to Sect. 6.2. During the workshop, each of these building blocks is explained in an interactive way, ensuring that participants understand the content and relevance. After this, workshop participants are asked to build specific strategies for each building block in teams.

\footnotetext{
${ }^{8} \mathrm{An}$ example is the soya goussi in Benin. This byproduct of soybean processing is full of protein and therefore a good alternative to poultry meat. Since the soya goussi is over $30 \%$ cheaper than poultry meat, it makes protein more affordable for BoP consumers.
} 
Each workshop ends with a half-day discussion on planning the next key step: implementation. Once the general BoP marketing strategy is defined, activities are identified to implement the strategy, and a budget for these activities is established. This is input that will be integrated into the broader annual action plan that forms the main document for implementation of the overall partnership agreement.

\subsubsection{Implementation}

After intense discussions on market insights and strategies, time for action is due. During and after the strategy workshop, all activities and responsibilities have been formulated and formalized into the broader action plan and thereby form part of the broader partnership. It is also for this reason that the respective partnership facilitator $^{9}$ is an active participant in the abovementioned strategizing.

The BoP marketing expert and the partnership facilitator work closely together with the business champion in the implementation of activities. Sometimes there might be a need for specific external experts or marketing agencies. In this case, 2SCALE facilitates the process of bringing in such parties. These types of experts are often needed in technical product formulation (e.g., developing a recipe for nutritional porridge), marketing material development, or product certification.

There are three key milestones throughout the implementation stage. The first is to have the actual product ready. This sounds straightforward but, depending on the situation, it might be challenging to get the right ingredients, product formulation, machinery, or production setup in place. The second milestone is getting the packaging finalized. This includes having a clear value proposition, brand, communication strategy, and actual packaging design and finding the right party that has the right packaging material available. When these milestones are reached, the business champion has an actual physical product that is ready to be sold in the market and should suit BoP consumers' aspirations in terms of affordability and acceptability.

The third milestone is to launch a market activation campaign. This step has proven to be one of the most crucial components of implementation. Having an actual product ready for sales and distribution at the factory gate is just the start. There needs to be awareness among the consumers about the new product and it needs to be available in the market. To achieve this, the business champion and 2SCALE develop a market activation campaign that follows the ATEAR (attention, trust, experience, action, retention) framework that is highlighted in Sect. 6.2. In short, awareness is created by organizing several activities to promote the brand and product and engage local communities. Availability is created by working closely with local shopkeepers, social networks, and possibly sales agents to get the product to the consumer.

\footnotetext{
${ }^{9} \mathrm{~A}$ partnership facilitator is a 2SCALE staff member who is responsible for facilitating the overall partnership.
} 


\subsubsection{Evaluate and Follow-Up}

The final stage of the process is to evaluate the pilot and to prepare the business champion for follow-up, which often consists of a strategy to either scale active marketing and distribution support by 2SCALE or exit the program and continue independently. This stage often starts with a meeting, during which the business champion reflects on the pilot, develops lessons learned, and shares ambitions toward the future. Based on that, together a follow-up strategy is developed. Looking back at the portfolio of pilots, there are four different outcomes of this stage:

- Optimization: The first outcome is when the business champion requests to continue to work together with 2SCALE to optimize the BoP marketing approach. This, for example, happened in the soybean partnership in Ethiopia with business champion GUTS Agro. During the evaluation, they realized that after successful product development and marketing, the next challenge was to safeguard the affordability of the product - a challenge that occurred mostly in their distribution model. Based on this workshop, GUTS Agro and 2SCALE designed a second phase of the pilot focusing on last-mile distribution.

- Replication: The second outcome is when the business champion sees potential to replicate the pilot activities in another geographical location but is not yet ready to do this alone. For example, with Shalem Investments in the sorghum partnership in Kenya, it was decided to replicate the pilot, which mostly focused on product launch and market activation. The pilot was originally implemented in Meru and was to be replicated in Thika.

- Financing: The third outcome is when the business champion sees opportunities for scale but is lacking the capital to finance growth of the model. In this scenario, 2SCALE supports the business champion in their business plan development and making relevant connections with the finance sector. For example, during our pineapple partnership with business champion Promo Fruits in Benin, 2SCALE supported Promo Fruits in developing a business plan to attract investments to scale its newly established micro-distribution model.

- Exiting: The fourth outcome is when the business champion feels sufficiently capacitated to continue independently. Eventually, all business champions will "exit" the program one way or another. However, that does not mean that all ties are broken. On the contrary, the business champion remains part of the 2SCALE network and often functions as a role model or mentor for other business champions.

\subsection{Key Tools, Approaches, and Implementation Strategies}

In this section, we present the tools and approaches that we use in the steps mentioned under Sect. 6.2 to develop implementation strategies for the pilots. Subsequently, we present the four generalized implementation strategies that we have seen materialize in the different pilots implemented over the past years. 


\subsubsection{Tools and Approaches}

When building BoP marketing pilots together with the business champion during strategy workshops, several tools have proven to be of crucial value. These tools were adopted by 2SCALE from the Business Model Canvas and contextualized by the 2SCALE team. All of the tools are hands-on, practical, and co-creative so that they can be used in workshops and understood by low-literate participants. It is interesting to see that the same tools have worked for vegetable farmers in Ethiopia as well as for soybean processors in Benin.

\subsubsection{Business Model Canvas}

The Business Model Canvas (BMC) is a tool that maps out the various key components of an organization and shows how the various components work together (Osterwalder and Pigneur 2010). The primary value for business champions is that the BMC shows the entire layout of their business. Moreover, it shows how an additional activity, such as targeting the BoP, can have implications for other parts of the business. The goal is for business champions to understand their business, the implications of the pilot, and the required strategy to make a pilot successful.

The main components that are always used in workshops and that form the basis for pilots are as follows:

- Persona: A persona is a fictional character that represents a typical consumer that a business champion aims to target. Examples of features that are covered in the persona include consumer demographics, pains, and gains. The purpose of building a persona is to have an in-depth understanding of the persona's wants and needs, which helps the business champion in designing the value proposition.

- Value proposition: A value proposition is an elaborated description of the product or service that the business champion is selling to his or her consumer. More specifically, it shows how a product or service creates gains or reduces pains for the consumer. The overall goal is to create a product-market fit, ensuring that the value proposition is relevant for the target consumer.

\subsubsection{Product and Pricing Strategy}

As mentioned in the previous section, it is crucial for a business champion to have a clear and competitive product and pricing strategy in comparison to its competitors. To get to such a strategy, it is helpful to visit sales points and purchase competitive products. With the business champion, the competitive products are organized in terms of price and value. Finally, the champion has to determine where to position his or her (new) product. A good example comes from the sorghum partnership 
in Kenya with business champion Shalem Investments, which positioned its brand in the relatively lower segment in terms of pricing. However, Shalem used a premium plastic packaging material with a modern design and was able to do this at a relatively low price point. This has made the brand distinguishable from its competitors, which used more basic packaging with poorly designed product labels. Even though it sounds straightforward, this interactive exercise has proven its value in developing a clear product and pricing strategy.

\subsubsection{ATEAR Marketing Model}

This is one of the most important tools to build a BoP pilot and forms the foundation for a business champion to build an entire marketing campaign. In summary, the ATEAR model covers five crucial steps: attention, trust, experience, action, and retention (Fig. 6.2). During the workshop, the team ideates on each of the steps and builds a marketing campaign plan that follows all five steps in a structured way. The ultimate goal is that the business champion develops a coherent and comprehensive campaign instead of only focusing on one element of ATEAR.

- Attention: The first step is the most straightforward one - getting attention. If a new product is launched in the market, consumers need to be aware of it. To create this awareness, several activities can be organized. These can be common above- or below-the-line marketing activities, such as radio advertisements, market activations, or community messaging. In defining the activities, it is key to understand which channels reach the target customer and which are seen as trusted channels.

- Trust: Attention alone is not sufficient. Consumers need to trust a new brand. There are many different brands out there that seek attention, so how do you stand out and create trust? Trust takes time and can be built by consistently "showing up" as a company and delivering quality products. Having the right food safety certification or product endorsement by a public or trusted person from the community can be a valuable asset to building trust.

- Experience: The proof of the pudding is in the eating. If a consumer cannot experience, or more specifically taste, the product, they will not immediately be inclined to purchase a new product, because the "risk" of buying something that, for instance, does not taste good or have the right texture will be too high. That is why tasting sessions are often held during market activations, allowing prospective consumers to try small samples of the product.

- Action: When the consumer is finally convinced to buy the product, he or she sometimes needs a final push to actually make the purchase. It can help if a particular promotion action is available, for instance, buy three items and pay for two, in which a consumer is rewarded for making a larger (and therefore more economical) purchase. 


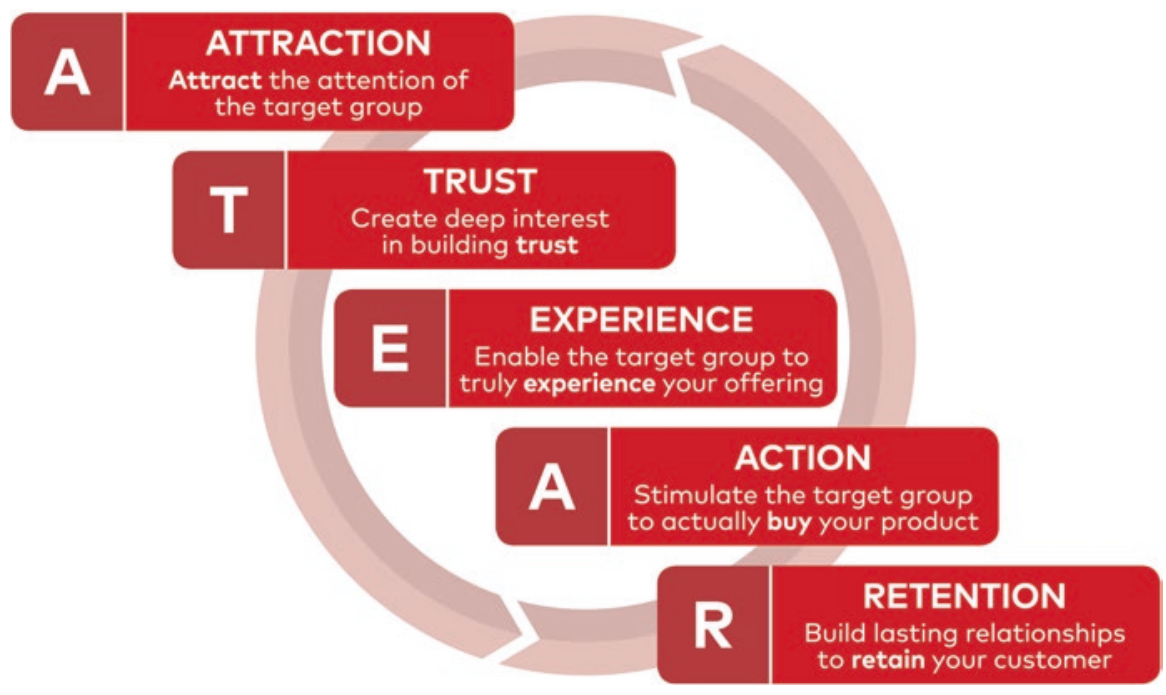

Fig. 6.2 ATEAR marketing model

- Retention: Getting new consumers to buy your product is essential, but in the world of fast-moving consumer goods (FMCGs), it is much more important to retain consumers and make sure they keep buying your product. Furthermore, it is much more expensive to create a new customer than to keep an existing one. Even though the short time span of BoP marketing pilots did not always allow for implementation of retention activities, loyalty activities were sometimes implemented, for instance, through cards that consumers can save to get a product for free.

All business champions have to compete in the market with other brands. Therefore, it is crucial that they come up with a brand and product that are distinct and take up a competitive position within the market. For this, 2SCALE developed a branding tool. In essence, the tool explains that a successful brand would need to:

- Resonate with the consumer

- Differentiate itself from competitors

- Express the internal values of the organization

For the first two criteria, the aforementioned persona and product and pricing strategies are used. For mapping the internal values, the first step is to define the core and aspirational values of the organization. These are summarized in the "brand (wo)man," having a single overview that captures the most important values of the organization. Secondly, a brand-archetype model is used, featuring eight different archetypes. An archetype is a typical representation of a certain set of personal traits and summarized in a set of "emotional values." After these steps are covered, the organization has a clear sense of its brand and communication strategy. This strategy 
provides clarity on the development of the organization's brand, packaging, and marketing materials. At the end of the session, the team develops conceptual directions for their packaging design.

\subsubsection{BoP Distribution Modeling}

Especially for business champions that have not yet been actively selling products in retail, distribution can be a key bottleneck to success. Distribution at the BoP level is a challenge for both local SMEs and cooperatives as well as for large multinationals. The main reason is that distribution and retail are not well organized at the BoP. BoP consumers are more difficult to reach and often remotely located from conventional markets or retail outlets, not just in rural areas but also in urban ones. This presents a serious challenge to reach the BoP consumer in an efficient and cost-effective manner. The majority of BoP consumers still make most of their purchases at open markets, local kiosks, or mom-and-pop stores - often owned by a single business owner. The BoP distribution model suggests three different approaches that business champions can explore within their specific market. These are as follows:

- Using existing channels and infrastructure (piggybacking)

- Creating hybrid partner-ships with nonprofit partners

- Setting up micro-franchised distribution models

The extent to which (a combination of) any of these three options can apply to a business champion strongly depends on two types of trade-offs (Fig. 6.3). One is the investment the business champion is able and willing to make in relation to the power or control the champion wants to have over the actual distribution activities.

The second trade-off relates to the speed at which the business champion wants to set up their distribution activities versus the level of competitiveness that the distribution model can bring to the actual product distributed.

The different characteristics of these three approaches are described in more detail under the following section on implementation strategies.

\subsubsection{Implementation Strategies}

Even though each pilot is unique and dependent on local market circumstances, we can distinguish four main implementation strategies for a BoP marketing pilot. Sometimes a pilot only consists of implementing one particular strategy; in other cases, several strategies are implemented in one pilot. 

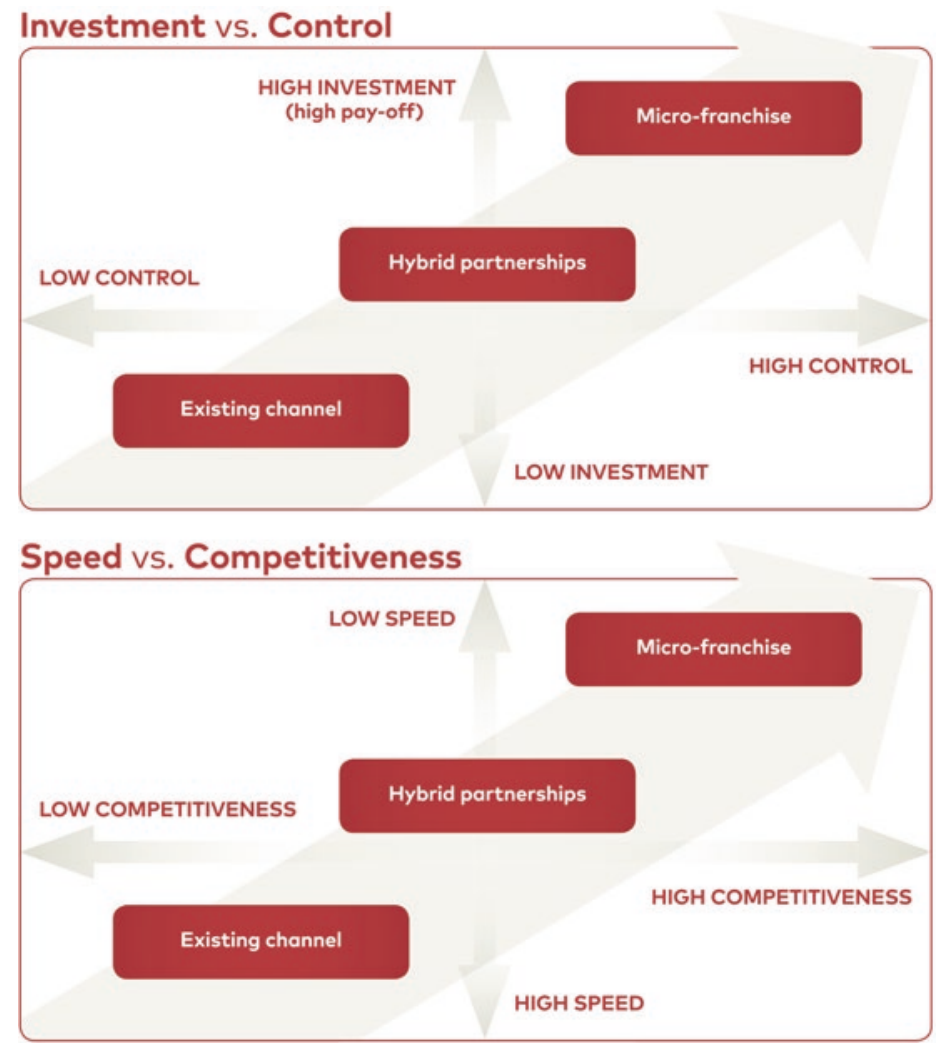

Fig. 6.3 Key trade-offs in the BoP-focused distribution models

\subsubsection{Product Development}

In the development of a pilot with a business champion, we often notice that after initial needs assessments and market research are conducted, the existing product portfolio of the business champions does not match the needs and wants of the local BoP consumer market. This means that 2SCALE will work with the business champion on developing a completely new product or will adapt the existing product in such a way that better suits the needs and wants of BoP consumers.

These processes can be quite time consuming and require a significant investment of resources from the business champion. But equally, they can provide a breakthrough for the company in entering the BoP market. In these cases, the market insights collected are used to shape the idea for a new product, and the product is subsequently further developed.

Sometimes this means that external expertise is needed, especially on the technical side. For example, a food technologist (i.e., through the Dutch "Programma 
Uitzending Managers" [PUM] program ${ }^{10}$ ) was brought in to assist with one pilot. Also, at this point, we use some of the tools and approaches mentioned above to ensure that the product is appealing and aspirational to BoP consumers. Quite often, several iterations of the product are done, based on tasting sessions that are held with test panels of BoP consumers to better understand their appreciation of the product. Eventually, the product is launched or introduced on the (local) BoP market.

GUTS Agro in Ethiopia is a good example of a pilot where a completely new product was introduced (Box 6.3). In this example, the business champion was already producing a blend of corn and soybean for the World Food Program and other relief organizations. However, the company aspired to enter the BoP consumer market directly. To do this, it had to develop the product completely from scratch, based on the corn and soybean blend it was already producing in bulk. The market insights gathered in Ethiopia were used to develop a porridge formula consisting of corn and soybean and fortified with vitamins and minerals. This formula was developed in close collaboration with an expert from PUM. 2SCALE further supported the business champion to develop a new product name, tagline, packaging, and pricing strategy, leading to the introduction of the new "Supermom" product for the BoP market in Ethiopia.

\section{Box 6.3 Business Champions - Snapshot: GUTS Agro, Ethiopia}

GUTS Agro Industry is an ISO 222000-certified food-processing company in Ethiopia, producing a range of goods from cereal to table salt and baby food. 2SCALE has supported Engidu Legesse, CEO of GUTS Agro, to develop a micro-franchise distribution model called "Likie."

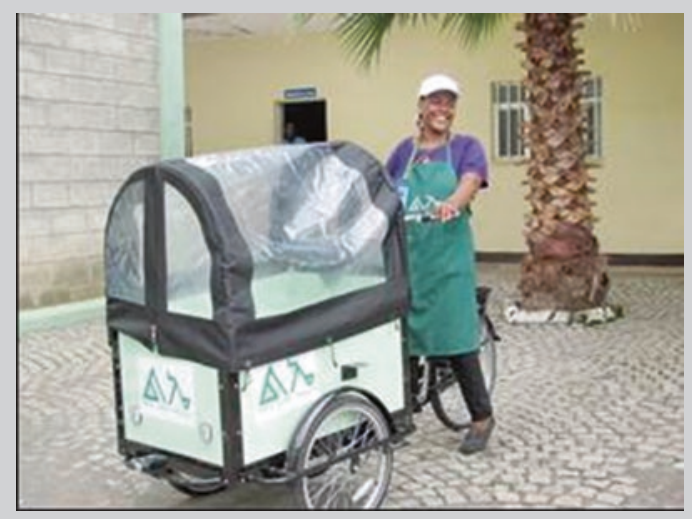

The Likie model is designed to effectively reach low-income consumers while maintaining the affordability of the product. The model uses female micro-franchisees to distribute a low-cost, high-protein, corn-soybean blend

(continued)

${ }^{10} \mathrm{https} / / /$ www.pum.nl/ for further information. 
(continued)

known as Supermoms, also developed with 2SCALE assistance. The Likie distribution model is now operating in several areas in Ethiopia and is supported by marketing activities.

This five-day campaign featured three well-known musicians who led a promotional campaign in schools, marketplaces, and low-income neighborhoods. Every morning for a week, the musicians, accompanied by GUTS Agro staff and saleswomen, would visit a school. The infotainment included a quiz contest on nutrition, with GUTS Agro products as prizes.

Likie is not only about nutrition, but also about empowering women. "Likie Ladies" are provided with uniforms, branded bags, and a tricycle to transport their goods door to door. They receive training, business support, and stocks on credit.

For GUTS Agro, Likie is more than a distribution network. It is also a way to help improve health and nutrition among the poor while helping budding women entrepreneurs create new businesses with very low start-up costs.

In other cases, adjustments were made to existing products so that these products would better fit BoP consumer demands. In Benin, under the soybean partnership, 2SCALE worked with business champion Coopérative de Transformation, d'Approvisionnement et d'Ècoulement de Soja (CTAE) on the BoP marketing of a soybean-based product called soya goussi. CTAE was already producing and selling soya goussi, but the packaging was unappealing, and the product was prepared under unhygienic circumstances. Plus, the size of the product did not appeal to the consumer. Based on these insights, CTAE and 2SCALE came up with an improved way of producing the soya goussi, leading to a higher-quality product at the same cost, which was better appreciated by the consumer. It was also sold in larger-sized and higher-quality packaging, with a label that provided information on product characteristics, which was missing previously. Consumers responded positively to these changes, which contributed to a $15-20 \%$ increase in sales, compared to the original product.

\subsubsection{Branding}

Even though branding could be seen as part of a product development strategy, we describe it here separately, because the importance of good branding, particularly to the BoP, is often largely underestimated. Companies tend to refrain from investments in branding and use very basic packaging, promotion, and other branding materials or do not have the capacity in-house to develop such branding materials. At the same time, the product itself not only needs to be of good quality or well priced, but it also needs to look good, and the broader brand needs to appeal to BoP consumers to help express the company's values. A successful brand meets three key criteria: 
- Appeals to the customer

- Is distinct from the competition

- Represents the values of the organization

The relevant tools for this strategy are the persona, value proposition, and branding. As an example, 2SCALE supported Shalem Investments in Kenya in product and brand strategy, developing a nutritious porridge targeted at the BoP (Box 6.4). The first step was to develop a product formula that met the nutritional needs and taste palate of the Kenyan BoP consumer. Once the product formula was finalized, the key challenge was to develop a brand strategy and packaging design. To ensure the brand appealed to the customer, Shalem conducted consumer research. The key conclusion from this work was that customers were highly aspirational and concerned by the quality of the product. To meet these preferences, Shalem developed a modern and colorful brand in quality, printed pouches - ensuring that the product had a high sense of perceived quality. This strategy directly allowed Shalem to differentiate itself from its competitors, who were mostly still using printed paper bags with limited colors. Finally, Shalem had a strong vision for its organization that was incorporated in the new packaging design: embracing an energetic and empowering view on providing quality nutrition.

\section{Box 6.4 Business Champions - Snapshot: Shalem, Kenya}

Founder of Shalem Investments, Ruth Kinoti, is one of 2SCALE's Kenyan business champions. Prior to joining the 2SCALE program, Shalem focused on the aggregation and sales of farmers' produce, such as maize, beans, sorghum, and soybeans. During the 2SCALE program, Shalem transformed into processing and marketing goods under the brand name Asili Plus in the Kenyan retail sector.

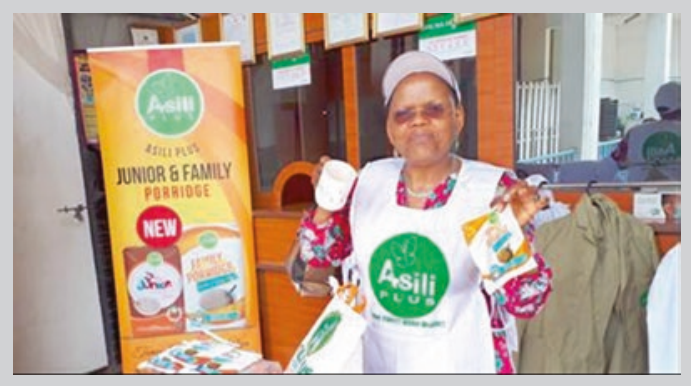

Over the course of 3 years, Shalem has passed all five steps of the 2SCALE journey. At the core of this journey was the added value for sorghum targeted to consumers. We facilitated co-creation workshops to identify gaps in the market and consequently develop a branding and distribution strategy. The outcome was a re-branded porridge flour that was affordable for BoP consumers. The packaging was also designed and developed considering strict country regulations on plastic use. 
(continued)

To promote it and make it available, a marketing and distribution strategy was developed and implemented. In just a few short weeks after launching her new marketing strategy, using a small pool of promoters, Kinoti reached 800 women in the community. For market activation, a tent was built at one of the largest open markets in Meru, the Gakoromone market. There were music events, talks on nutrition, and 10 brand ambassadors, young women and men, who introduced the product to vendors and customers in the market.

Over 2000 people were reached during those market days, which took place once a week for 3 weeks. The customers had the opportunity to taste the Asili Plus porridge flour and received promotional items, such as free T-shirts, after purchasing more than four packets of the porridge.

Shalem Investments plans to grow its business by replicating the marketing and distribution strategy to other parts of the country, which will triple its income. The women involved during the pilot will be part of the microfranchising model, in which they will continue selling the Asili Plus fortified flour as an income-generating activity.

Another example of brand development comes from our groundnut partnership located in the Ivory Coast. The business champion, the Komborodougou Women's Cooperative, previously sold unbranded groundnut paste in simple plastic bags. By selling the groundnut paste in this very basic packaging, it was difficult for consumers to distinguish their product from other similar products. Eventually, together with 2SCALE, a new type of packaging was selected - small plastic containers. Along with a newly developed brand, which was applied to the plastic containers, the brand concept characterized the region where the product was produced, making the branding also easily applicable to any other products the cooperative would develop in the future.

\subsubsection{Market Activation}

Earlier in this chapter, we introduced the ATEAR model as a critical building block for BoP market activation activities. These market activations are meant to bring (new) products to the attention of prospective consumers, and let them experience the product, ideally in the presence of a recognizable, trusted role model, to increase the likelihood that the prospective BoP consumers will trust the product. Market activations are often held at locations where BoP consumers typically come to buy their products (such as open markets during market days) or at places where peers meet or trusted people can be found. Examples of these are activations in women's groups (like Chamas in Kenya) and around churches or community halls in the presence of local religious or community leaders. Sometimes, activations are specifically targeted at a particular audience. In the case of the soy kebab pilot in North-East 
Ghana, part of the broader soybean partnership, we identified the significant potential of selling nutritious snacks (soy kebabs) through local schools, instead of the sweets and cookies that were usually sold there. In this particular case, the market activation fully focused on schoolchildren (Box 6.5).

\section{Box 6.5 Business Champions - Snapshot: Banda Borae, Ghana}

Banda Borae Cooperative is one of the more grassroots partners with which 2SCALE developed BoP marketing activities. It is a processing group of 20 women, who process and sell soybean kebabs in Kpandai, rural northern Ghana. The cooperative initially marketed their soybean kebabs at the local village market, without a branding or retail strategy.

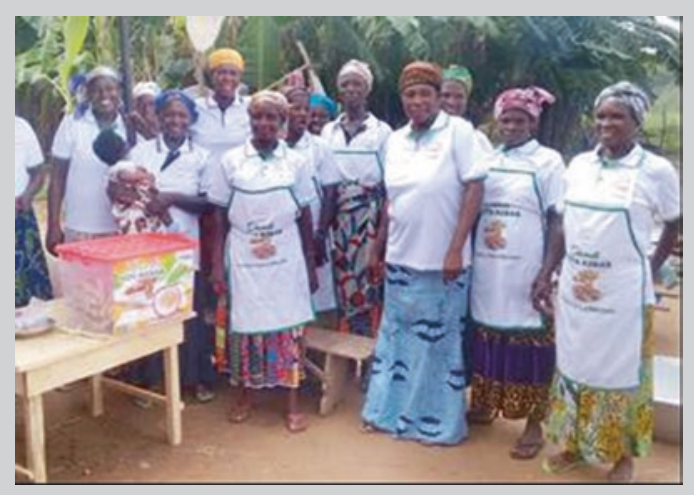

Sales were seemingly effective, especially on market days in Kpandai, when all the other villages came together to buy and sell goods. However, sales remained stable and little growth was achieved.

Together with 2SCALE, the cooperative managed to expand its route to market by introducing a branded container as a sales outlet in a number of schools. This solution came about during the Business Model Canvas workshop and discussion on marketing issues. The strategy was supported by stakeholder engagement with school authorities (school heads and teachers) to directly target the schoolchildren for nutritional purposes.

The partnership also developed a mobile channel (containers) to enable women to sell soybean kebabs in branded containers and attire in various locations to enhance their appeal and visibility, which turned out to be the most effective distribution strategy.

Over the course of a short six-month pilot period, these two marketing channels increased sales of the kebabs on a daily basis, from an initial average of 150 sticks to 500 sticks per retailer. The cost of a stick of kebab is 10 Ghana pesewas (US \$0.02) and provides a nutritious, protein-rich alternative to the sugary snacks schoolchildren would otherwise purchase. 
During market activations, the product is often introduced in a playful and fun way, for instance, in combination with dancing, singing songs, and playing music. MCs ensure visitors are enthusiastic about what is happening and create a buzz. Next to the physical location where the activation is held, vans or other motorized vehicles tour the neighborhood to gather a larger crowd to the location of the market activation. In Ethiopia, during the market activations with business champion Family Milk, as part of the larger dairy partnership, locally celebrated singers were involved in the market activation. In Nigeria, a market activation for a Tom Brown product in Kaduna state greatly benefited from the visit of the governor's wife to the activation activities. And obviously, a critical element in all market activations is to provide consumers the opportunity to taste the product.

Lastly, coupons or other actions are sometimes introduced to attract consumers during the activation to buy the product at a discount (the Action in ATEAR). These market activations are also the right moments to inform potential BoP consumers about the importance of nutrition. In the aforementioned pilot on soy kebabs, activities were developed, together with school teachers, to educate the children on the importance of a healthy diet and how that could improve their performance both at home and in school. Combining the general benefit of such activities, the schoolchildren also better understand why it is more beneficial for them to buy a proteinrich soy product instead of sugary snacks; this will help drive demand for the soy kebab sticks.

\subsubsection{Last-Mile Distribution}

Even when a product is available and properly marketed, there are no guarantees that the product will actually reach BoP consumers. This was clearly the case in the first pilot 2SCALE delivered with GUTS Agro, where together we developed the Supermom product completely from scratch and ran an intensive marketing campaign to promote the product. However, the product uptake was less than expected, and distribution was a larger than expected part of the challenge.

As mentioned earlier, BoP consumers are typically removed from conventional market outlets. This means that sales points have to be located closer to the consumer, or distribution should be organized in such a way that it directly reaches the consumer. Previously we referred to three strategies through which such "last-mile distribution" can be organized in a way that does not become too costly and the end product too expensive. ${ }^{11}$

- Use of existing channels and infrastructure: The first and easiest approach is to use existing distribution channels, also referred to as "piggybacking." To explore such approaches, the business champion needs to investigate the existing channels in the BoP target market. For example, there could already be a distributor active in the market that sells other, non-competing FMCGs such as bottled

\footnotetext{
${ }^{11} \mathrm{http} / / /$ bopinc.org/updates/publication/access-to-food-and-nutrition-at-the-bop
} 
water. If this distributor has sufficient reach, the business champion could explore a potential collaboration. The advantage is that such an approach may reduce the business champion's own investment in setting up a distribution system. Also, this can be done quite quickly and easily. The disadvantage is that there is limited control. Therefore, it is often suggested that business champions build initial sales themselves before involving external distributors.

- Hybrid partnerships: The second approach is to explore hybrid partnerships. The difference from the first strategy is that hybrid partnerships focus on organizations that are not primarily focused on selling FMCGs. These could be nongovernmental organizations (NGOs), microfinance institutions (MFIs), self-help groups (SHGs), or cooperatives. For example, an NGO that works on promoting health messages in a $\mathrm{BoP}$ community might also be interested in promoting and selling nutritious porridge. The benefit of such a hybrid partnership is that there might be strong synergies, without any pressing business competition. The downside is that hybrid partnerships can take quite some time to establish, and they can be political in nature. These partnerships are not necessarily driven by business acumen, limiting their commercial viability.

- Micro-franchise: The final strategy is the micro-franchise model, in which a business champion works on setting up a network of individual microentrepreneurs. These micro-entrepreneurs can function as sales agents, either by having a small shop or pushcart or going door to door. The product portfolio that these agents sell can exclusively belong to the business owner or include other FMCGs. Building such models requires significant investment. All the agents need to be recruited, trained, and provided with marketing materials and stock. After that, it requires thorough management to ensure the agents perform well. The main advantage of this approach is that the business champion has better control of aspects such as pricing, product placement, and more. It can take years before the model is fully operational and has reached scale. It is often a model that has high appeal among business champions; however, it is important to keep these challenges in mind before adopting such an approach.

As mentioned above, GUTS Agro's Supermom food product did not sell as fast as we had expected. So, the business looked at a more direct distribution method that utilized different wholesalers and increased GUTS Agro's control over distribution. Ultimately this led to the setup of the Likie Ladies' network, a network of around 100 independent female sales agents that distribute GUTS Agro's products door to door.

Also, as part of the pineapple partnership in Benin, business champion Promo Fruits set up a micro-franchised network of sales agents, as it wanted to have control over the distribution and sales of its fruit juice. Additionally, it was an opportunity to spark micro-entrepreneurship locally. It was also a good way to access firsthand customer feedback through the agents that interacted with consumers daily. At the same time, the model was relatively cost intensive, so Promo Fruits developed a business plan for the distribution network to secure working capital to tackle cash flow challenges (Box 6.6). 


\section{Box 6.6 Business Champions - Snapshot: Promo Fruits, Benin}

Back in 2000, a group of pineapple producers, led by Dieudonné Alladjodjo, unsuccessfully tried to develop different trading relations with larger offtakers in Benin, Nigeria, and the European Union. The group decided that processing pineapple juice for the local market was more commercially viable and created the Pineapple Recovery Initiative (IRA) cooperative, with starting capital of US $\$ 5,000$ and a processing capacity of $200 \mathrm{~kg}$ of pineapple per day. The IRA cooperative gradually increased its processing capacity to $5,000 \mathrm{~kg}$ per day in 2009.

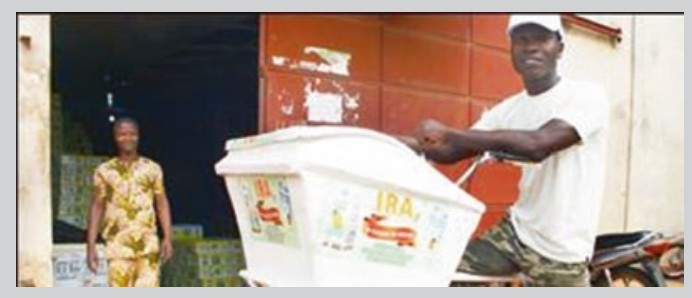

Then in 2011, the IRA cooperative was transformed into a company with limited liability (SARL) and 100\% of its shares distributed among IRA member producers. The company's processing capacity increased from 5 to 45 tons per day.

The business model of Promo Fruits is based on four pillars:

1. The company sources from small-scale pineapple producers in Benin, including 2,580 producers grouped into nine professional organizations.

2. Promo Fruits produces $100 \%$ natural juice, for which the company has been able to develop a national and sub-regional market.

3. The company offers producers a competitive and incentivizing price, which motivates and retains producers and allows the factory to guarantee its supply.

4. Promo Fruits intervenes upstream in the value chain by facilitating the access of producers, who are members of the sourcing network, to an input credit system.

Over the course of collaboration between Promo Fruits and 2SCALE, the company's management indicated the intent to focus more specifically on BoP markets. Without changing the nature of the product (natural fruit juice), new packaging was developed. Smaller SKUs were produced to increase affordability, and a micro-franchise model was tested; initially, there were 15 sales agents, (five on cargo bikes, five with pushcarts, and five on foot, going door to door), all selling not only the juice but also making combinations with sandwiches. The agents performed well, and at the end of the collaboration between 2SCALE and Promo Fruits, a business model was written to attract funding to sustain the network independently. 
In Ghana, via the soybean partnership, business champion Yedent Agro took another approach by piggybacking off the existing networks of "koko sellers"12 through which the company decided to distribute and sell its Maisoy Forte Tom Brown mix. This was a good channel for Yedent Agro to expand its exposure toward BoP consumers. However, this strategy limited the company's influence over the final sales price of the product, which was determined by the koko sellers themselves. This became a beneficial strategy for Yedent Agro. They first wanted to test this new model on a smaller scale and with limited resources before considering scaling up. However, the first test with the koko sellers was so successful that the company decided to continue with the model and scale it up.

\subsection{Lessons Learned}

During the program, the 2SCALE team collected different lessons learned, as this rather pioneering work with African food-producing SMEs and farmer organizations did not always run smoothly. The following are a few lessons learned that could help strengthen the potential for success of any programmatic approach to BoP marketing.

\subsubsection{The Opportunity Is Real}

In the beginning of the design and implementation of the 2SCALE program, it was not foreseen that the BoP marketing pilots would become a key intervention in several of the partnerships. During the program, the value of the BoP marketing pilots became apparent to the project partners and the business champions. Especially when the first successful cases were established, other business champions were motivated to follow a similar path. This development has shown us that the pilots not only offer value for the program and champions involved but also that there is a real market opportunity in terms of serving the BoP with nutritious quality foods. BoP consumers have proven to be open to try, use, and repeatedly purchase the products that were launched by the champions. So yes, the opportunity is real from yoghurt to porridge and soy drinks! For all pilots that were implemented, the majority are still running and serving the BoP. This is the reason that for the second phase of the 2SCALE program, the official target is to reach one million consumers, necessitating that 2SCALE continues to support more business champions accessing local BoP markets and serving them with nutritious food products.

\footnotetext{
${ }^{12}$ Koko is a common type of warm porridge that is produced on the spot by street vendors called "koko sellers." They run their preparation and sales out of simple stalls on the roadside across Ghana.
} 


\subsubsection{Consumer-Centered Approach Is New for Most Business Champions}

As explained in this paper, one of the first steps in building a pilot is to develop an in-depth understanding of the market and the consumers. This consumer-centered approach is sometimes considered as a default way of approaching new business development. However, for most business champions in the 2SCALE program, this was a novel and new approach. For some champions, it was a struggle to have to first invest in research before being able to take action. Even though the business champion could target its new products at local communities next to the factory, it was still a big step to actually go out in the market and gain a deep understanding of the end consumer. Ultimately, all successful champions did embrace this more lean, consumer-centered approach. In the 2SCALE program, it has therefore been a critical step in all BoP marketing pilots and will be included in future partnership development.

\subsubsection{Actionable Insights as Catalyst for Progress}

At the start of the 2SCALE program, significant time and resources were invested in conducting general market research on the specific 2SCALE sectors in the various countries. However, it became clear that this general market data provided little use for the business champions. In short, market data is not the limiting factor for champions to develop products and marketing strategies. Instead, business champions search for tangible product and market opportunities, applying a lean approach in leveraging these opportunities. During the course of the program, 2SCALE tailored its approach by conducting smaller market/consumer research activities that were tailored to the specific business champions. This resulted in actionable insights that the business champions actually could use, such as a practical way of mapping local competitors, pricing, and understanding consumer desires and behavior. Once it became apparent that these practical and actionable insights were useful for the champions, this research approach was further integrated across the program.

\subsubsection{Transformation of the Business Champion Is Needed}

Particularly for business champions that have a business that is not (yet) dealing directly with end consumers but rather with other businesses or governments, BoP marketing (or any other direct consumer marketing) is a radically different type of business. Instead of dealing with large volumes, contracts, and buyers, the BoP market progresses in a slower and more gradual manner. In addition, a creative approach is required to understand consumer needs and desires and, in turn, build relevant products and marketing strategies. Suddenly CEOs need to make decision 
on various "creative considerations," such as what label designs, colors, and images are needed. It also requires a different approach in distribution and sales, dealing with many small volumes and a large number of cash transactions. All in all, working in the business-to-consumer (B2C) channels requires a specific set of qualities and skills that many business champions did not have at the start of the partnership. In some cases, the business champion did not manage to make this adjustment and/ or build a B2C team. However, those that did succeed made that adjustment and transformed their business approach radically. For instance, GUTS Agro is now working with over 100 sales agents that all require dedicated product supply, dayto-day support, and training. Based on these experiences, the 2SCALE program now aims to prepare business champions in more detail on building successful B2C channels and its related transformation in thinking. Again, the lessons learned from the first business champions have helped tremendously in preparing others. That is why 2SCALE also promotes cross-learning between champions and organized field trips to successful case studies for new or potential business champions. Perhaps most importantly, the business champions are guided through this journey by the 2SCALE team.

\subsubsection{Activating the Market Is a Must}

Another key learning has been the crucial value of activating the market, from the market product launch to the related promotional activities. Selling a new product to the BoP is not easy and does not happen by itself. Introducing the product into local supermarkets or simply selling it to wholesalers and sales agents is not enough. It requires a clear and specific strategy, including which distribution channels will be used (e.g., women groups) and which marketing activities will be organized (e.g., tasting sessions) in order to accelerate product sales. This approach is explained in detail in this paper, and it has been proven repeatedly as a fundamental step to help kick start a business. At the same time, both the business champion and 2SCALE have to be cautious of the relatively high cost of such market activations and make clear arrangements on how these costs can be shared to be as equitable as possible. Now that there are several successful case stories on market activation, it becomes easier for business champions to replicate certain approaches. Cross-learning between champions is therefore facilitated in the program as well as promoting learning and results via blogs and videos.

\subsubsection{Getting Stuck by Missing or Broken Machinery}

As mentioned in Sect. 6.2 under conducting a needs assessment, 2SCALE learned that it is critical for the success of a pilot that a business champion has the right machinery in place and is ready for production, especially when dealing with larger 
business champions that produce processed and/or packaged foods and rely heavily on machinery to produce their food products. In several cases, pilots were heavily delayed or did not progress further than the strategy phase, because the product simply could not be produced due to the delayed procurement of the right machinery (or the right volumes of raw materials) or lack of local technicians available to service or fix machinery that broke down or did not function properly. This makes all the preparatory work a waste of time and does not fit the context of piloting, where approaches and strategies will need to be tested under a short time span. Doing a proper assessment with the business champion on their "capacity to produce" is paramount, and one should be cautious with promises regarding bank loans to be secured, grants to be received, or technical support to be available.

\subsubsection{Adhering to Food Safety Regulation Is of Essence}

In many of the pilots, the strategizing activities eventually led the business champion to come up with a completely new food product. However, if a company comes along with a new product, especially when the company has finished "market testing" their new product and wants to launch the product in a larger market, the new product often will need to be tested by the food safety authorities and receive a certification that it meets food safety requirements. In some instances, these processes have proven to be very time and resource intensive; particularly with the smaller business champions, management did not always have the right expertise or capacities in place to deliver on the different requirements or requests for information that these government agencies ask for. Therefore, in different instances, as part of an exit strategy, 2SCALE has supported the business champion in meeting the requirements to get their product approved and certified by food safety agencies.

\subsubsection{Preventing Adverse Environmental Effects}

In several of the BoP marketing pilots, new products were developed, or new stock keeping units (SKUs) of products were introduced. Often, these developments also cause larger volumes of packaging materials, often plastic, to be introduced to the market. When not addressed properly, this increase in packaging materials could lead to substantially more plastics to be dumped as garbage and affect the environment. This challenge is not just specific to 2SCALE and touches many different market-led initiatives focusing on BoP markets. Large multinationals like Unilever acknowledge the challenge and are looking at alternative, often biodegradable, packaging options. In the future, 2SCALE will look at opportunities for introducing more environmentally friendly packaging options or working with companies on recycling of their own waste streams, bearing in mind at the same time that this should not add prohibitive additional costs to the business model. 


\subsubsection{Measure the Impact of Activities on a Consumer Level}

It was mentioned earlier that at the beginning of 2SCALE, it was not foreseen for the program to undertake BoP market activities beyond doing market research and sharing outcomes with business champions. When 2SCALE started to engage more actively with business champions in $\mathrm{BoP}$ marketing pilots and implemented $\mathrm{BoP}$ marketing activities, no system was put in place to measure their impact due to the piloting nature of the activities. In many of the pilots, sales figures and other general business information on the pilot's performance was shared by the company. However, there was little understanding to what extent the pilots actually contributed to a nutritious and/or more affordable diet for BoP consumers. The understanding of the impact at the consumer level remained very generic and indirect. For example, in Benin, we brought a soy-based product on the market that could substitute white meat (containing around the same protein level as the meat) at a $30 \%$ lower price, making nutritious food available at more affordable prices, an assumed positive consumer impact. As 2SCALE is a program that strives to make a developmental impact, it is critical that in the future, the program implements better systems to measure the effect of BoP marketing activities at a consumer level.

\subsection{Looking Ahead}

Since January 2019, a second phase of the 2SCALE program commenced, offering new opportunities to take a more extensive approach toward BoP markets and nutritious food products. This translates into an additional program target that is different from the first phase, namely, a target focused on consumers. The second phase aims to improve affordable access to a nutritious diet for one million BoP consumers. To reach this goal, the lessons learned described in this section will be used to create a more rigorous approach to BoP marketing. There are several approaches that 2SCALE will take to create a bigger impact for BoP consumer markets, in comparison to the impact achieved during the earlier phase.

First, the results of BoP marketing pilots from the first phase will be used to showcase to new business champions, helping to clearly demonstrate that the market opportunity at the BoP is real. We expect that the success of business champions - Shalem Investments in Kenya, Promo Fruits in Benin, Yedent in Ghana, and the more grassroots business champions, such as the Danaya cooperative producing attieke in Mali or the Funtua women's group producing fura in Nigeria - will inspire other food-processing SMEs and producer organizations to do the same. Welldocumented case studies will be used to create this ripple effect. We will do this not only through face-to-face encounters, but also through digital learning, such as webinars and podcasts - all building on the experience and insights from the first phase. 
Another mechanism for increased impact is replication. Overall, the second phase will have a stronger focus on sector transformation, ensuring that the impact of 2SCALE goes beyond individual partnerships and transforms entire sectors. For instance, building BoP market propositions around the processing of soybeans in Nigeria should not only positively impact the business champion with whom this work is undertaken, but ideally it should impact the entire soybean production sector in Nigeria and even beyond, inspiring like-minded entrepreneurs in other countries where 2SCALE is active.

There will also be more room in the program to work on BoP marketing. During the first phase of 2SCALE, BoP marketing was delivered in a limited, pilot format working with short timeframes and minimal budgets. Marketing pilots were also undertaken in less than half of the 53 partnerships that were mobilized. In the second phase of 2SCALE, the target is to have a BoP marketing component in at least 40 of the anticipated 60 partnerships and to have at least five of these 60 partnerships primarily focused on BoP markets. For this, the in-country expertise on BoP marketing across all eight 2SCALE countries will be expanded.

The focus also will increase on nutrition. The program will further involve nutrition experts to help assess the nutritional value of the different products developed under the BoP marketing approaches, to ensure all products developed under BoP marketing activities are more nutritious than the current alternatives in the market. From the demand point of view, in close synergy with market activations to be undertaken, 2SCALE will look at the opportunity to develop activities that focus on behavioral change in nutrition to help create more awareness with BoP consumers on the importance of nutrition and to influence their purchasing and consumption behavior for the better when it comes to food products. This will not only have a potentially positive impact on the health of consumers, it will also create demand for the food products that are developed under BoP marketing activities, creating new market opportunities for our business champions.

Finally, the importance of partnerships with other programs, organizations, or companies must not be forgotten here. The new and ambitious target of providing access to a more nutritious and affordable diet for one million BoP consumers will need smart collaborations. This way, 2SCALE can share its lessons learned on BoP marketing and, at the same time, leverage the networks of other organizations and programs that also work on the implementation of business-led approaches to marketing and distributing nutritious food to the BoP.

\subsection{Concluding Remarks}

As mentioned in the last section, the 2SCALE program is extended with 4 years and will run until 2023. The approach and lessons learned will be leveraged with the agribusinesses that will be part of the second phase of 2SCALE. Apart from that, it is our wish that this chapter will be useful for other agribusiness and incubator 
programs. We hope you find those business cases inspiring and the lessons learned useful as we all work toward a more sustainable and viable food system in lowincome markets.

\section{References}

Osterwalder A, Pigneur Y (2010) Business model generation: a handbook for visionaries, game changers, and challengers, vol 288. Wiley, Hoboken

Prahalad CK (2009) The fortune at the bottom of the pyramid: eradicating poverty through profits. Pearson Education Publishers, United States. 358 p

Open Access This chapter is licensed under the terms of the Creative Commons Attribution 4.0 International License (http://creativecommons.org/licenses/by/4.0/), which permits use, sharing, adaptation, distribution and reproduction in any medium or format, as long as you give appropriate credit to the original author(s) and the source, provide a link to the Creative Commons license and indicate if changes were made.

The images or other third party material in this chapter are included in the chapter's Creative Commons license, unless indicated otherwise in a credit line to the material. If material is not included in the chapter's Creative Commons license and your intended use is not permitted by statutory regulation or exceeds the permitted use, you will need to obtain permission directly from the copyright holder. 